\title{
PORTAL HYPERTENSION DUE TO ECHINOCOCCUS ALVEOLARIS: A CASE REPORT
}

\author{
Orhan Kursat Poyrazoglu', Huseyin Ataseven ${ }^{1}$, Sevim Bektas ${ }^{2}$, Ayse Aydin ${ }^{3}$, Mehmet Yalniz ${ }^{1}$, Selman Celebi ${ }^{1}$, \\ Ibrahim Halil Bahcecioglu
}

Firat University, School of Medicine, Turkey: Divison of Gastroenterology ${ }^{1}$, Department of Internal Medicine ${ }^{2}$, Department of Radiology $y^{3}$

Summary: Infection of the liver with Echinococcus alveolaris (EA) contemplates with a fatal course though it is a rare condition. We present herein a patient with upper gastrointestinal bleeding due to portal hypertension caused by the involvement of the liver with EA.

Key words: Echinococcus alveolaris; Liver; Portal hypertension

\section{Introduction}

Infection of liver with Echinococcus alveolaris (EA) contemplates with a fatal course though it is a rare condition. EA enlarges through its outer membrane compared to $E$. granulosus. Cyst has been surrounded with the fibro-inflammatuar response of the host. Consequently, occlusion occurs in the intra-hepatic bile ducts, hepatic veins and branches of the portal vein. Subsequent to liver involvement, the lesion grows up locally or metastasizes to the lung, brain, bone, and bulbus oculi as a malignant tumor $(8,12)$. We shall present here a case of EA, which might be encountered it various clinical forms, referred to our clinic with upper gastrointestinal bleeding due to portal hypertension.

\section{Case}

A 57-years old male was referred to the emergency room with symptoms of gastrointestinal bleeding. He depicted four times of hematemesis and two times of melena in the last 24 hours. For nine years he was treated with albendazole $2 \times 400 \mathrm{mg} /$ day for the suppression of a cyst of microbial origin. The patient, with irregular follow-up in a variety of different clinics, was admitted to the gastroenterology clinic for the first time with this symptom.

During the physical examination, the patient was faint and scleras subicteric. The spleen was palpable $2-3 \mathrm{~cm}$ beneath the subcostal margin, and the liver $7-8 \mathrm{~cm}$ below the subcostal margin. The liver, with a dumb contour and stiff consistence, was filling the whole epigastrium. There was no ascites.

In laboratory evaluation the values of the biochemical parameters were as follows: AST: $40 \mathrm{IU} / \mathrm{L}$, ALT: $23 \mathrm{IU} / \mathrm{L}$,
LDH: 356 IU/L, GGT: 69 IU/L, ALP: 352 IU/L, T. Bil: 1.6 mg/dl D.Bil: $0.6 \mathrm{mg} / \mathrm{dl}$ Urea: $64 \mathrm{mg} / \mathrm{dl} \mathrm{Cr:} 0.7 \mathrm{mg} / \mathrm{dl} \mathrm{Na}$ : $133 \mathrm{mg} / \mathrm{dl}, \mathrm{K}: 4.7 \mathrm{mg} / \mathrm{dl}$, Total Protein: $8.8 \mathrm{gr} / \mathrm{dl}$, Albumin: $2.1 \mathrm{gr} / \mathrm{dl}$, PT: 15.8 second. The bleeding time was 4 minutes. In the complete blood count; hemoglobin was $8.5 \mathrm{gr} / \mathrm{dl}$, hemotocrit $25 \%$, white blood cells $8800 / \mathrm{mm}^{3}$, and platelets $289000 / \mathrm{mm}^{3}$. In ultrasonography, a cystic mass at a length of $5.5 \times 6 \mathrm{~cm}$ with a central hypoecoic echogenity and a thick wall was detected in the right lobe of the liver. The length of the spleen was $17 \mathrm{~cm}$.

In further evaluation; hepatitis markers were negative. Additionally, tumors markers were in normal range. In the upper gastrointestinal endoscopy, grade 3 actively bleeding varices with red spots were observed in the esophagus. Esophageal varices treated with an endoscopic band ligation stopped the bleeding. In the duplex Doppler ultrasonographic evaluation, portal vein diameter and flow speed were found increased. The flow pattern was hepatopedal. The liver was $21 \mathrm{~cm}$ in length and had lobular contours in upper magnetic resonance (MR) imaging of the abdomen. The size of the lateral segment of the left lobe was increased $5.5 \times 6 \mathrm{~cm}$ of middle segment of right and left lobes was observed as heterogonous intensity with central necrosis areas. The size of spleen was $17 \mathrm{~cm}$. Serologic evaluation by ELISA was positive. The portal vein proximal to the branch of the right and left portal vein could not be observed in MR portography due to pressure secondary to the cyst.

In addition to the treatment of actively bleeding esophageal varices, long-term treatment of the patient was discussed in a council consisting of gastroenterology, radiology, and general surgery departments. Although percutaneous drainage and radical surgery are the initial treatment options for the treatment of portal hypertension due to EA, 
presence of invasion to the right and left portal vein branches detected in the radiological evaluation hampered these modalities and the patient was referred to a transplantation center for the treatment of portal hypertension.
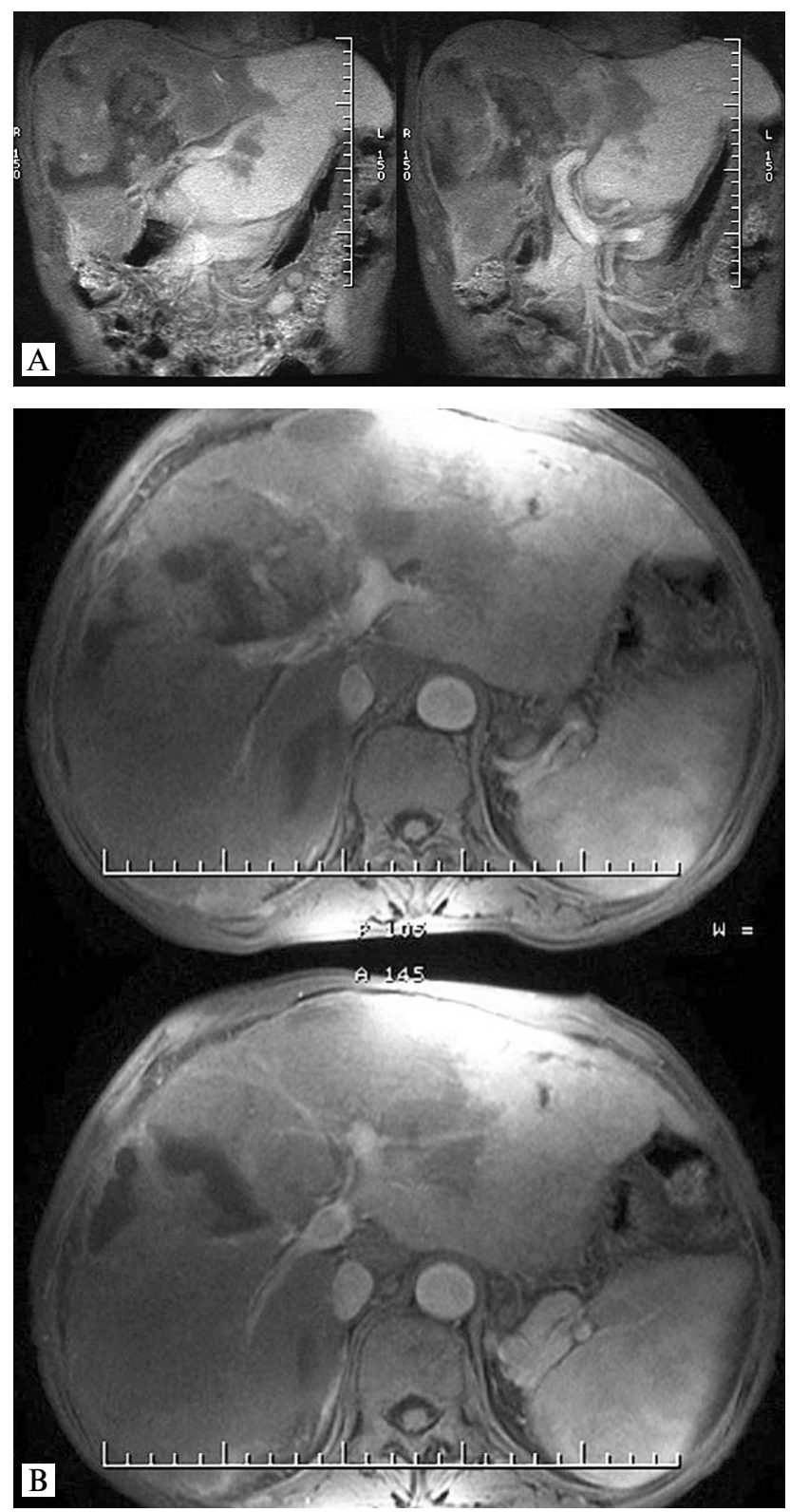

Fig. 1: A - Coronal T1A Fat Sat contrast-enhanced image; B - Axial T1A Fat Sat contrast-enhanced image.

In coronal and axial T1A Fat Sat contrast-enhanced images; liver contours are lobulated. The intensity of the right lobe and the medial segment of the left lobe of the liver remarkably decreased (hypointens areas). In addition, necrosis areas, more hypotens images, are seen prominently. The lateral segment of the left lobe is intact. The main portal vein, left portal vein and partly its segmental branches proximal to the right portal vein and partly posterior segmental branches are seen.

\section{Discussion}

Echinococcosis is a zoonotic infection caused by Echinococcosis spp. It is a worldwide known, important helmintic infection. It has been seen as endemic in East Europe, Mediterranean countries, East Africa, South America, Far East countries, and Australia $(9,12)$. In Turkey there are two forms known as E. alveolaris and E. granulosis. The first case of EA was reported in 1939 (1). The clinical course of the disease represents a wide diversity. The disease may contemplate without any sign for years, although severe complications culminating in death may also occur.

There are three main therapeutic strategies for hepatic E. alveolaris and E. granulosis. These are chemotherapy, surgery, and percutane drainage. Initially, chemotherapy was given to the patient. Albendazol 2x400 mg/day had been used for nine years. The patient followed-up by several clinics, however, did not apply to clinicians in a regular manner. Nonetheless, he received the given remedies regularly. Administration of albendazole appears as a more accurate clinical approach for such cases due to its superior absorption from the gastrointestinal system and bio-availability compared to mebendazole $(10,13,14)$.

Some investigators have demonstrated that long-term follow-up of albendazole chemotherapy has culminated in a cure $(4,6)$. Nevertheless, Frider et al. (5) showed that patients might have a symptom free course for years regardless of cyst size and type. The case presented in this study, however, was a progressive disease, albeit under albendazole treatment for a long time. The cyst enlarged locally although no distant metastasis occurred. The patient had gastrointestinal bleeding after a long symptom free period. This clearly suggests that cases like this should be under close and more cautious follow-up even though patients are generally symptoms free.

Other important and preferred treatment approaches for cases of liver EA are percutaneous drainage and radical surgery $(2,3,7,11)$. Nonetheless, invasion to the right and left portal vein branches have been detected in radiological evaluation. The patient, without distant and extra-hepatic metastasis, was determined as being in grade $3 \mathrm{~b}$ system of human EA classification, according to PNM ( $\mathrm{P}$, hepatic parasite localization; $\mathrm{N}$, neighbouring structure involvement; $\mathrm{M}$, metastases). (8). Consideration from this point of view did not allow for performing treatment options like percutaneous drainage and surgery in this case. However, some investigators point out that some patients may require liver transplantation $(8,14)$. Hence, the presented case was referred to a transplantation center.

In conclusion, there is yet no measure for prevention of the EA usually seen in the eastern part of our country. Hence, it is still an important health issue. In this context, early diagnosis is of eminent importance and the cases should be followed closely, even in the absence of any symptom and signs. It appears that radical surgery should be kept in mind in non-responders to chemotherapy due to 
complications that eventually might be fatal. Nonetheless, liver transplantation might also be taken into consideration as a cornerstone of the treatment.

\section{References}

1. Altintas N. Past to present: echinococcosis in Turkey. Acta Tropica 2003;85:105-12. 2. Aygun E, Sahin M, Odev K, et al. The management of liver hydatid cysts by percutaneous drainage. Can J Surg 2001:44:203-09.

3. Filice C, Brunetti E. Use of PAIR in human cystic echinococcosis. Acta Trop 1997;64:95-107.

4. Franchi C, DiVico B, Teggi A. Long-term evaluation of patients with hydatidosis treated with benzimidazole carbamates. Clin Infect Dis 1999;29:304-09.

5. Frider B, Larrieu E, Odriozola M. Long-term outcome of asymptomatic liver hydatidosis. Journal of Hepatology 1999;30:228-31.

6. Horton R. Albendazole in treatment of human cystic echinococcosis: 12 years of experience. Acta Trop 1997;64:79-93.
7. Khuroo M, Wani N, Javid G, et al. Percutaneous drainage compared with surgery for hepatic hydatid cysts. N Engl J Med 1997;337:881-7.

8. McManus DP, Zhang W, L Ji, Bartley PB. Echinococcosis. Lancet 2003;362 1295-304.

9. Meyers WC, Kim RD, Chari RS. Echinococcal cysts. In: Townsend CM, Beauchamp RD, Evers BM, Mattox KL, editors. Sabiston textbook of surgery: the biological basis of modern surgical practice. Philadelphia: WB Saunders, 2001;1053-5.

10. Saimot AG. Medical treatment of liver hydatidosis. World J Surg 2001;25: $15-20$.

11. Sato N, Namieno T, Furuya $K$, et al. Contribution of mass screening system to resectability of hepatic lesions involving Echinococcus multilocularis. J Gastroenterol 1997;32:351-4.

12. Seimenis A. Overview of the epidemiological situation on echinococcosis in the Mediterranean region Acta Tropica 2003;85:191-5.

13. Senyuz OF, Yesildag E, Celayir S. Albendazole therapy in the treatment of hydatid liver disease. Surg Today 2001;31:487-91.

14. Smego Jr. RA, Sebanego P. Treatment options for hepatic cystic echinococcosis International Journal of Infectious Diseases 2005;9:69-6

Submitted November 2006. Accepted February 2007.

\section{Corresponding author:}

Orhan Kursat Poyrazoglu, M.D., Firat University, School of Medicine, Department of Internal Medicine, Section of Gastroenterology,

23200, Elazig/Turkey, e-mail: okpoyrazoglu@yahoo.com 